\title{
Ethnic differences in the relationship between body mass index and percentage body fat among Asian children from different backgrounds
}

\author{
Ailing Liu ${ }^{1,2}$, Nuala M. Byrne ${ }^{2}$, Masaharu Kagawa ${ }^{3}$, Guansheng Ma ${ }^{1}$, Bee Koon Poh ${ }^{4}$, \\ Mohammad Noor Ismail $^{4}$, Kallaya Kijboonchoo ${ }^{5}$, Lara Nasreddine ${ }^{6}$, Trinidad Palad Trinidad ${ }^{7}$ \\ and Andrew P. Hills ${ }^{2 *}$ \\ ${ }^{1}$ National Institute of Nutrition and Food Safety, Chinese Center for Disease Control and Prevention, Beijing, China \\ ${ }^{2}$ Institute of Health and Biomedical Innovation, Queensland University of Technology, Brisbane, Australia \\ ${ }^{3}$ Institute of Nutrition Sciences, Kagawa Nutrition University, Saitama, Japan \\ ${ }^{4}$ Universiti Kebangsaan Malaysia, Kuala Lumpur, Malaysia \\ ${ }^{5}$ Institute of Nutrition, Mabidol University at Salaya, Nakhon Pathom, Thailand \\ ${ }^{6}$ Department of Nutrition and Food Sciences, Faculty of Agriculture and Food Sciences, American University of Beirut, \\ Beirut, Lebanon \\ ${ }^{7}$ Department of Science and Technology, Food and Nutrition Research Institute, Manila, Philippines
}

(Received 20 September 2010 - Revised 17 January 2011 - Accepted 16 February 2011 - First published online 31 May 2011 )

\begin{abstract}
Overweight and obesity in Asian children are increasing at an alarming rate; therefore a better understanding of the relationship between BMI and percentage body fat $(\% \mathrm{BF})$ in this population is important. A total of 1039 children aged 8-10 years, encompassing a wide BMI range, were recruited from China, Lebanon, Malaysia, The Philippines and Thailand. Body composition was determined using the ${ }^{2} \mathrm{H}$ dilution technique to quantify total body water and subsequently fat mass, fat-free mass and \%BF. Ethnic differences in the BMI-\%BF relationship were found; for example, $\% \mathrm{BF}$ in Filipino boys was approximately $2 \%$ lower than in their Thai and Malay counterparts. In contrast, Thai girls had approximately $2 \cdot 0 \%$ higher $\% \mathrm{BF}$ values than in their Chinese, Lebanese, Filipino and Malay counterparts at a given BMI. However, the ethnic difference in the BMI-\%BF relationship varied by BMI. Compared with Caucasian children of the same age, Asian children had 3-6 units lower BMI at a given \%BF. Approximately one-third of the obese Asian children (\%BF above $25 \%$ for boys and above $30 \%$ for girls) in the study were not identified using the WHO classification and more than half using the International Obesity Task Force classification. Use of the Chinese classification increased the sensitivity. Results confirmed the necessity to consider ethnic differences in body composition when developing BMI cut-points and other obesity criteria in Asian children.
\end{abstract}

Key words: Body composition: Ethnicity: Asian children

Obesity, commonly defined as an excess of body fat, is a global problem with rapid increases seen in both developed and developing countries. BMI has achieved international acceptance as a standard approach to define obesity; however, the index has a number of limitations, including the inability to distinguish fat mass and fat-free mass (FFM). These limitations may be even more important when attempting to compare individuals from different ethnic groups.

Body composition appears to be ethnicity dependent ${ }^{(1)}$ and many studies have identified an ethnic variation in the relationship between percentage body fat (\%BF) and BMI among Caucasian and Asian adults ${ }^{(2-4)}$. Some studies have also shown similar ethnic differences in the relationship between $\mathrm{BMI}$ and $\% \mathrm{BF}$ among white, black and Asian children $^{(5-11)}$. For example, white children have a higher \%BF than blacks for a given BMI after controlling for sex and maturation stage, but a lower \%BF than Asian children at the same BMI. However, the relationship between BMI and $\% \mathrm{BF}$ in children is further complicated by variations in growth rates and maturity levels ${ }^{(12,13)}$. In addition, the BMI$\%$ BF relationship also differs among Asian adults from different origins, with Indians having the highest \%BF and Chinese the lowest for the same BMI when comparing Chinese, Malays and Indians living in Singapore ${ }^{(14)}$. However, there are comparatively fewer data to indicate differences in the BMI-\%BF relationship among Asian children from different origins.

The lack of comprehensive assessment of the ethnic differences between $\mathrm{BMI}$ and \%BF in children makes it difficult to

Abbreviations: \%BF, percentage body fat; FFM, fat-free mass; IOTF, International Obesity Task Force; TBW, total body water.

*Corresponding author: Professor Andrew P. Hills, fax +61 7 31386030, email a.hills@qut.edu.au 
formulate an appropriate obesity classification system based on BMI with relevance for Asian children. Therefore, despite the availability of a number of international classification systems for paediatric obesity based on $\mathrm{BMI}^{(15,16)}$, national variants still exist ${ }^{(17)}$. In summary, a lack of data and also controversy around the optimal classification system make it difficult to monitor global and national trends, to make comparisons between studies and to stratify for public health measures. Therefore, the purpose of the present study was to further investigate the relationship between body composition and anthropometric characteristics of children from different Asian backgrounds.

\section{Methods}

\section{Participants}

In the present study five countries were involved, including one East Asian country (China), one West Asian country (Lebanon) and three South-East Asian countries (Malaysia, The Philippines and Thailand). In each country, a nonrandom purposive sampling approach was used which aimed to enrol children of both sexes encompassing a wide BMI range for each year of age between 8 and 10 years. A total of 1039 participants ( 534 boys and 506 girls) were recruited, including: 352 Chinese children (202 boys and 150 girls) living in Beijing, China; 155 Lebanese children (seventy-four boys and eighty-one girls) living in Beirut, Lebanon; 197 Malay children (105 boys and ninety-two girls) living in Kuala Lumpur, Malaysia; 112 Filipino children (fifty-one boys and sixty-one girls) living in Manila, The Philippines; and 223 Thai children (101 boys and 122 girls) living in Bangkok, Thailand. Ethnicity was determined by self-identification and those whose parents were identified as having the same origin were included. Additional inclusion criteria required that participants be at Tanner stage 1 of puberty and free from any diagnosed medical condition that might potentially interfere with body composition measurement.

The present study was conducted according to the guidelines of the Helsinki Declaration and all procedures were approved by the University Human Research Ethics Committee, Queensland University of Technology. Written informed consent was obtained from all participants and/or their parent(s).

\section{Anthropometric measurements}

Height was measured to the nearest $0 \cdot 1 \mathrm{~cm}$ using a portable stadiometer (Holtain, Crymych, Pembs, UK). Body weight was measured to the nearest $0 \cdot 1 \mathrm{~kg}$ using a $\mathrm{SECA}^{\mathrm{TM}}$ electronic scale (Hamburg, Germany). Participants were measured in the morning wearing only underwear after urinating. BMI was calculated as body weight ( $\mathrm{kg}$ ) divided by the square of height $(\mathrm{m})$. Overweight and obesity were defined on the basis of a sex-specific BMI-for-age reference, as recommended by the International Obesity Task Force (IOTF) ${ }^{(15)}, \mathrm{WHO}^{(16)}$ and Group of China Obesity Task Force ${ }^{(17)}$.
The pubertal status of each participant was assessed by trained investigators according to the criteria of Tanner \& Whitehouse $^{(18)}$.

\section{Body composition measurement}

Total body water (TBW) was assessed using the ${ }^{2} \mathrm{H}$ dilution technique. Before consuming a dose of the isotope, a $5 \mathrm{ml}$ sample of urine was collected to determine the basal ${ }^{2} \mathrm{H}$ level in the body. A $10 \%{ }^{2} \mathrm{H}$-labelled water dose of $0.5 \mathrm{~g}$ per $\mathrm{kg}$ body weight was given orally. A second urine sample was collected $5 \mathrm{~h}$ later to allow complete equilibration within the body water compartments. The enrichment of the pre-dose urine sample, post-dose urine sample, the dose given and the local tap water were measured by isotope ratio MS (IRMS, 20:20 Hydra Model; PDZ Europa, Crewe, Cheshire, UK). The ${ }^{2} \mathrm{H}$ dilution space was determined using the following equation:

$$
T B W(k g)=\frac{T A}{a} \times \frac{(E a-E t)}{E s-E p} \times \frac{1}{1.041},
$$
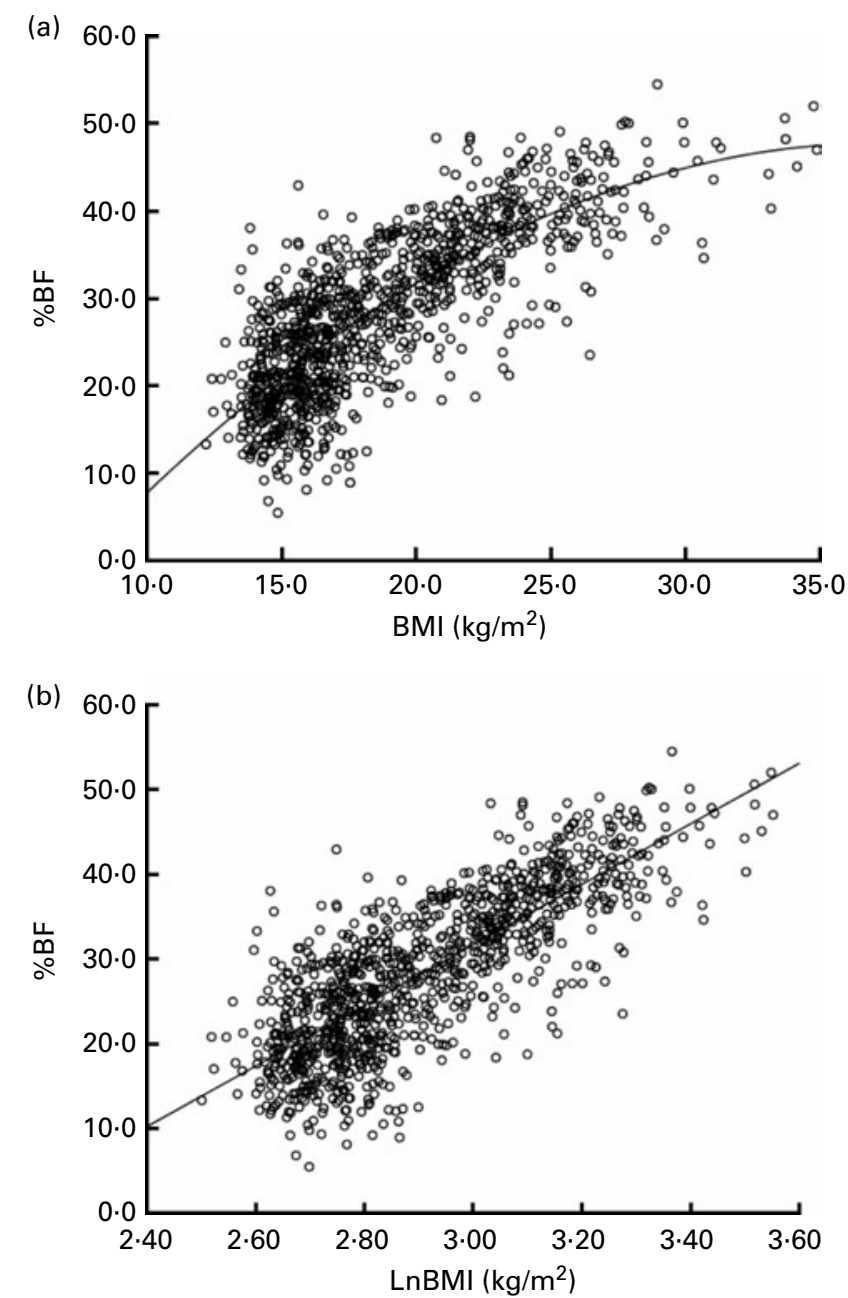

Fig. 1. Scatter plots of percentage body fat (\%BF) against BMI (a) and \%BF against natural log-transformed BMI (LnBMI) (b). 
where $T$ is the amount of tap water in which the dose was diluted in grams, $A$ is the amount of dose taken by the participant in grams, $a$ is the amount of the dose in grams retained for mass spectrometer analysis, and Ea, Et, Ep and Es are the isotopic enrichment in $\Delta$ units relative to standard mean ocean water of the diluted dose, the tap water used, the pre-dose urine sample and the post-dose urine sample. The constant (1.041) was used to adjust for the non-aqueous exchange of $\mathrm{H}$ atoms in the body. FFM was derived from TBW using a hydration coefficient, that is, the fraction of FFM comprised of water. Lohman's age- and sex-specific constants for hydration of FFM for children were used to calculate $\mathrm{FFM}^{(19)}$. The absolute fat mass was derived by subtracting FFM from weight, based on the two-compartment body composition model, and \%BF was then calculated.

\section{Statistical analysis}

A single regression model in which \%BF was regressed on BMI was used to identify outliers. There were five participants with standardised residual values above 3.3 or less than $-3 \cdot 3$; these were excluded from subsequent analyses ${ }^{(20)}$. Body composition results were expressed as mean values and standard deviations. Differences in body composition among age, sex and ethnic groups were tested by ANCOVA. Pearson's correlation was used to assess the correlation coefficient between $\mathrm{BMI}$ and \%BF. To test the significance of differences between correlation coefficients, all coefficients were transformed using Fisher's $z$-transformation and the $t$ test was used to test for the equality between the transformed coefficients. The relationship between \%BF and BMI throughout the entire biological range is curvilinear ${ }^{(21)}$. Therefore, natural log transformation of BMI (LnBMI) was performed to linearise the curvilinear relationship between $\% \mathrm{BF}$ and $\mathrm{BMI}^{(9,11,22)}$ (Fig. 1). Stepwise multiple linear regression analysis was conducted using \% $\mathrm{BF}$ as the dependent variable, with $\mathrm{BMI}$, age, sex (males $=1$ and females $=0$ ) and ethnicity as independent variables to determine the $\mathrm{BMI}-\% \mathrm{BF}$ relationship. The dummy variables for ethnicity were E1, E2, E3 and E4. For Chinese E1 =0,
$\mathrm{E} 2=0, \mathrm{E} 3=0$ and $\mathrm{E} 4=0$; for Lebanese $\mathrm{E} 1=1, \mathrm{E} 2=0$, $\mathrm{E} 3=0$ and $\mathrm{E} 4=0$; for Malay $\mathrm{E} 1=0, \mathrm{E} 2=1, \mathrm{E} 3=0$ and $\mathrm{E} 4=0$; for Filipino $\mathrm{E} 1=0, \mathrm{E} 2=0, \mathrm{E} 3=1$ and $\mathrm{E} 4=0$; for Thai $\mathrm{E} 1=0, \mathrm{E} 2=0, \mathrm{E} 3=0$ and $\mathrm{E} 4=1$. Homogeneity of regression slopes among the groups was examined by the significance of the interaction between the covariate and the group variables, which was tested by the general linear model. ANCOVA was used to compare differences in \%BF between different ethnic groups, taking differences in sex, age and BMI into account.

The validity and accuracy of BMI in the diagnosis of obesity were evaluated by calculating sensitivity, specificity and agreement rate, relative to obesity diagnosed by absolute $\% \mathrm{BF}$ (above $25 \%$ for boys and above $30 \%$ for girls ${ }^{(23)}$, using cross-tabulation. Sensitivity is the proportion of truly obese participants identified correctly as obese by BMI (true positives). Specificity is the proportion of truly non-obese participants identified correctly as non-obese by BMI (true negatives). The agreement rate is the proportion of all participants diagnosed correctly as obese and non-obese by BMI. The Caucasian prediction equation derived from Dutch children $^{(24)}$ was used to calculate the $\% \mathrm{BF}$ if their BMI was calculated using the cut-offs for obesity proposed by WHO. The predicted \%BF was then used to recalculate the BMI using the ethnic-specific prediction equation to obtain a BMI level for Asian children that is equivalent with the WHO cut-offs for obesity developed from the Caucasian population. All statistical analyses were performed with SAS 9.1 (SAS Institute, Inc., Cary, NC, USA); a two-sided $P$ value of $<0.05$ was regarded as statistically significant.

\section{Results}

The physical characteristics of 1039 pre-pubertal children by sex and ethnicity are detailed in Table 1. Participants ranged in BMI from 12.2 to $34.9 \mathrm{~kg} / \mathrm{m}^{2}$ and in $\% \mathrm{BF}$ from 5.5 to $54.5 \%$. After adjustment for age, significant differences were found in height, weight, BMI and \%BF of boys from different ethnic groups, and height and \%BF of girls.

Table 1. Characteristics of participants ${ }^{\star}$

(Mean values and standard deviations)

\begin{tabular}{|c|c|c|c|c|c|c|c|c|c|c|c|}
\hline & \multicolumn{2}{|c|}{ Chinese ( $n$ 352) } & \multicolumn{2}{|c|}{ Lebanese $(n 155)$} & \multicolumn{2}{|c|}{ Malay ( $n$ 197) } & \multicolumn{2}{|c|}{ Filipino ( $n$ 112) } & \multicolumn{2}{|c|}{ Thai $(n$ 223) } & \multirow[b]{2}{*}{$P$} \\
\hline & Mean & SD & Mean & SD & Mean & SD & Mean & SD & Mean & SD & \\
\hline \multicolumn{12}{|l|}{ Boys } \\
\hline Age (years) & $9 \cdot 4$ & $0 \cdot 8$ & 9.4 & 0.7 & $9 \cdot 4$ & 0.8 & $9 \cdot 0$ & 0.8 & $9 \cdot 4$ & 0.7 & 0.007 \\
\hline Height (cm) & $138 \cdot 5$ & $7 \cdot 2$ & $134 \cdot 8$ & 8.0 & $131 \cdot 4$ & $7 \cdot 0$ & $131 \cdot 3$ & $6 \cdot 2$ & $134 \cdot 7$ & $6 \cdot 6$ & $<0.0001$ \\
\hline Weight (kg) & $39 \cdot 3$ & $10 \cdot 9$ & $34 \cdot 7$ & $9 \cdot 7$ & $33 \cdot 1$ & $12 \cdot 0$ & $32 \cdot 6$ & 7.5 & 33.8 & $10 \cdot 1$ & $<0.0001$ \\
\hline BMI $\left(\mathrm{kg} / \mathrm{m}^{2}\right)$ & $20 \cdot 2$ & $4 \cdot 4$ & $18 \cdot 8$ & 3.7 & $18 \cdot 8$ & $5 \cdot 3$ & $18 \cdot 8$ & $3 \cdot 3$ & $18 \cdot 4$ & $4 \cdot 2$ & 0.003 \\
\hline Percentage body fat & $29 \cdot 2$ & $10 \cdot 0$ & $26 \cdot 3$ & $9 \cdot 6$ & $26 \cdot 9$ & $11 \cdot 3$ & 24.9 & $7 \cdot 3$ & $26 \cdot 5$ & 8.9 & 0.026 \\
\hline \multicolumn{12}{|l|}{ Girls } \\
\hline Age (years) & 9.4 & 0.8 & $9 \cdot 2$ & 0.7 & $9 \cdot 4 \cdot 0$ & 0.8 & 9.3 & 0.7 & 9.3 & 0.8 & 0.132 \\
\hline Height $(\mathrm{cm})$ & $136 \cdot 2$ & $7 \cdot 6$ & 133.4 & 8.0 & $133 \cdot 0$ & 9.5 & $132 \cdot 8$ & 7.5 & 134.5 & 8.0 & 0.0004 \\
\hline Weight (kg) & $34 \cdot 2$ & $9 \cdot 1$ & $31 \cdot 0$ & 7.4 & $33 \cdot 6$ & 9.5 & $33 \cdot 3$ & $7 \cdot 6$ & 34.3 & $10 \cdot 4$ & $0 \cdot 152$ \\
\hline BMI $\left(\mathrm{kg} / \mathrm{m}^{2}\right)$ & $18 \cdot 2$ & 3.5 & $17 \cdot 2$ & $2 \cdot 7$ & $18 \cdot 6$ & 4.7 & $18 \cdot 7$ & $3 \cdot 1$ & $18 \cdot 6$ & 4.1 & 0.061 \\
\hline Percentage body fat & 28.5 & 7.9 & $26 \cdot 9$ & $7 \cdot 6$ & $30 \cdot 0$ & $10 \cdot 4$ & $30 \cdot 2$ & $6 \cdot 5$ & $31 \cdot 8$ & $8 \cdot 6$ & $<0.0001$ \\
\hline
\end{tabular}

*All comparisons among ethnic groups were adjusted for age except for the comparison of age. 
Table 2. Pearson correlation coefficients between BMI and other body composition variables by sex and ethnicity*

\begin{tabular}{lccccc}
\hline & Chinese & Lebanese & Malay & Filipino & Thai \\
\hline Boys & & & & & \\
Height & 0.45 & 0.49 & 0.56 & 0.34 & 0.56 \\
Weight & 0.94 & 0.94 & 0.97 & 0.92 & 0.96 \\
Fat mass & 0.94 & 0.96 & 0.94 & 0.88 & 0.93 \\
$\begin{array}{l}\text { Fat-free mass } \\
\text { Percentage }\end{array}$ & 0.73 & 0.73 & 0.84 & 0.78 & 0.86 \\
$\quad 0.86$ & 0.89 & 0.81 & 0.67 & 0.84 \\
$\quad$ body fat & & & & & \\
Girls & & & & & \\
Height & 0.45 & 0.46 & 0.52 & 0.29 & 0.55 \\
Weight & 0.93 & 0.89 & 0.94 & 0.89 & 0.95 \\
Fat mass & 0.92 & 0.91 & 0.95 & 0.86 & 0.94 \\
Fat-free mass & 0.79 & 0.67 & 0.77 & 0.71 & 0.78 \\
Percentage & 0.77 & 0.80 & 0.77 & 0.63 & 0.80 \\
$\quad$ body fat & & & & & \\
\hline
\end{tabular}

*All correlations are significant $(P<0.0001)$ except for the correlation of BMI with height in Malay boys and in Filipino girls.

Correlations between BMI and body composition variables by sex and ethnicity are shown in Table 2. BMI was significantly and positively correlated with all variables, but no significant difference in the strength of correlation across ethnic groups was found.

Using stepwise multiple regression analysis, there was a significant ethnic difference in the BMI-\%BF relationship among Asian children. In boys, the model using Filipinos as a reference population was $\% \mathrm{BF}=39.60 \times$ LnBMI $+1.31 \times$ Malays $+1.42 \times$ Thais $-89.25\left(R^{2} 0.717\right.$; seE $\left.5.3 \%\right)$. After correcting for age and BMI, \%BF in Malays (27.7 (SE 0.5) \%) and Thai boys (28.1 (SE 0.5$) \%$ ) was 2.0 and $2.4 \%$ higher than in Filipino boys (25.7 (SE 0.8) \%). Moreover, the difference in $\% \mathrm{BF}$ between Malays and Filipinos and between Thais and Filipinos was more apparent as BMI increased. Despite no significant difference between Filipinos and Chinese and between Filipinos and Lebanese in corrected \%BF, the regression slopes differed significantly $(P<0 \cdot 05)$. Chinese and Lebanese boys tended to have lower \%BF than Filipinos at lower BMI values and $\% \mathrm{BF}$ at higher BMI levels. A similar corrected \% BF was found among Chinese (27.4 (SE 0.4) \%), Lebanese (27.1 (se 0.6) \%), Malay and Thai boys and no interaction between LnBMI and ethnicity was found in each pair of ethnic groups of Chinese, Lebanese, Malays and Thais (Fig. 2). In girls, the model using Filipinos as a reference population was $\% \mathrm{BF}=33.70 \times \mathrm{LnBMI}+2.31 \times$ Thais $-68.31\left(R^{2} 0.618\right.$; SEE $5 \cdot 3 \%)$. After correcting for age and BMI, $\% \mathrm{BF}$ in Thais $(31.1$ (SE 0.5$) \%$ ) was $1.6 \%$ higher than in their Filipino counterparts (29.5 (SE 0.7$) \%$ ) and the difference in \%BF between Thais and Filipinos was more apparent at a higher BMI level ( $F=7.50 ; P=0.007$ for the regression slopes comparison). Thai girls had $1.9 \%$ higher corrected $\% \mathrm{BF}$ compared with their Lebanese counterparts (29.2 (SE 0.6) \%) and the difference decreased with an increase in BMI $(F=12 \cdot 30$; $P=0.0006$ for the regression slopes comparison). Thai girls had 1.6 and $2.5 \%$ higher corrected $\% \mathrm{BF}$ than their Malay (29.5 (se 0.7) \%) and Chinese (28.6 (SE 0.4) \%) counterparts, respectively. In addition, there was no significant interaction term of LnBMI $\times$ ethnicity between Thais and Malays
( $F=3.39 ; P=0.067$ for the regression slopes comparison) and between Thais and Chinese $(F=-0.141 ; P=0.888$ for the regression slopes comparison). A similar corrected $\% \mathrm{BF}$ was found among Chinese, Lebanese, Malay and Filipino girls and no interaction between LnBMI and ethnicity was found in each pair of ethnic groups of Chinese, Lebanese, Malay and Filipino except for a significant difference in the regression slopes between Lebanese and Filipinos ( $F=2.567 ; P=0.011$ ). Lebanese girls tended to have lower $\%$ BF than Filipinos at a lower BMI level, while having a higher \%BF at a higher BMI level (Fig. 2).
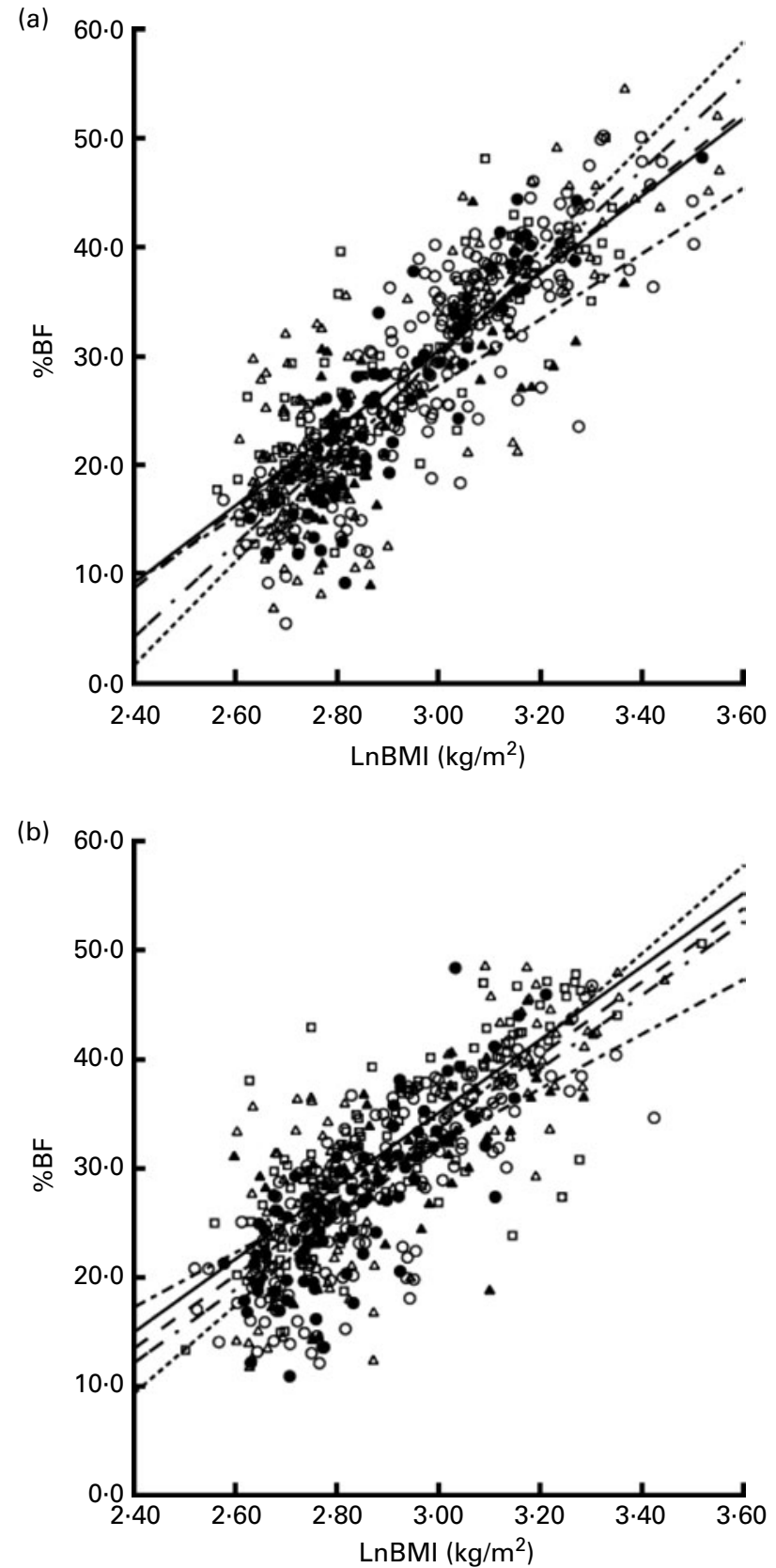

Fig. 2. Relationship between percentage body fat (\%BF) by the ${ }^{2} \mathrm{H}$ dilution technique and natural log-transformed BMI (LnBMI) of Chinese $(\bigcirc,--\cdot)$, Lebanese $(\bullet,--)$, Malay $(\Delta,---)$, Filipino $(\boldsymbol{\Lambda},---)$ and Thai $(\square,-)$ boys (a) and girls (b). 
Table 3 shows the sensitivity and specificity of BMI cut-off points for obesity, as defined by the WHO, IOTF and Chinese Obesity Task Force in identifying boys with a $\% \mathrm{BF}>25$ and girls with a $\% \mathrm{BF}>30$, by ethnic group. The sensitivity and specificity with the three criteria was dependent on ethnicity. Filipino boys showed the highest sensitivity with the WHO and the Chinese classification and Malay boys showed the highest sensitivity with the IOTF classification. Malay girls showed the highest sensitivity with all three classifications. Both Lebanese boys and girls showed the lowest sensitivity with all three classifications. When the WHO classification was applied to the five Asian countries, 52.6 to $61.5 \%$ of boys who had a \%BF above $25 \%$ were identified as obese and only 11.5 to $57.4 \%$ girls who had a $\%$ BF of above $30 \%$ were identified as obese. When the IOTF classification was applied, fewer boys and girls with excess body fat were identified ( $\chi^{2}$ test; $\left.P<0 \cdot 0001\right)$. In contrast, application of the Chinese classification increased the sensitivity to 29.6 to $59 \cdot 6 \%$ for girls, but reduced it to $44 \cdot 7$ to $53 \cdot 8 \%$ for boys.

Predicted \%BF from the Caucasian prediction equation derived from Dutch children was 22.3, 20.6, 21.5, 21.8 and $21.3 \%$ for Chinese, Lebanese, Malay, Filipino and Thai children, respectively. The predicted value was lower than the measured $\% \mathrm{BF}$ for the five ethnic groups, by $6.6 \%$ for Chinese, $6.0 \%$ for Lebanese, $6.9 \%$ for Malays, $5.9 \%$ for Filipinos and $7 \cdot 9 \%$ for Thais. Table 4 shows that the BMI scores of Asian children who had the same $\% \mathrm{BF}$ as Caucasians were 2.9 to $6.1 \mathrm{~kg} / \mathrm{m}^{2}$ lower than Caucasians. For example, Thai boys aged 8 years with a BMI of $15.7 \mathrm{~kg} / \mathrm{m}^{2}$ have the same level of $\% \mathrm{BF}$ as Caucasians with a BMI of $19 \cdot 7 \mathrm{~kg} / \mathrm{m}^{2}$.

\section{Discussion}

The present study indicates that the relationship between $\% \mathrm{BF}$ (as determined from TBW measured by the ${ }^{2} \mathrm{H}$ dilution technique) and BMI was dependent on ethnicity among the cohort of Asian pre-pubertal children from different origins.

The present results indicate that at an equivalent BMI level, Filipino boys had a lower \%BF compared with their Malay and Thai counterparts. Thai girls had a significantly higher \%BF compared with their Chinese, Lebanese, Malay and Filipino counterparts. Despite the limited number of studies to determine the difference in the BMI-\%BF relationship among Asians from different backgrounds, evidence suggests that there is a difference in both children and adults. East Asians (Chinese) had a lower \%BF than South (Indian) ${ }^{(25)}$ and South-East Asians (Malays) ${ }^{(26,27)}$ at a given BMI, sex and age. Although the present study did not find a significant difference in the BMI-\%BF relationship between Chinese and Malay children, it is interesting to compare the ethnic differences in the BMI-\%BF relationship among South-East Asian populations. Malay and Thai boys had a significantly higher \%BF than Filipino boys and Thai girls had a significantly higher \%BF than Malay and Filipino girls at a fixed BMI, despite both groups living in similar climatic conditions and having similar food supply. To date, there is little published information on differences in the BMI-\%BF relationship among these ethnic groups. Lebanon lies far to the West of Asia and

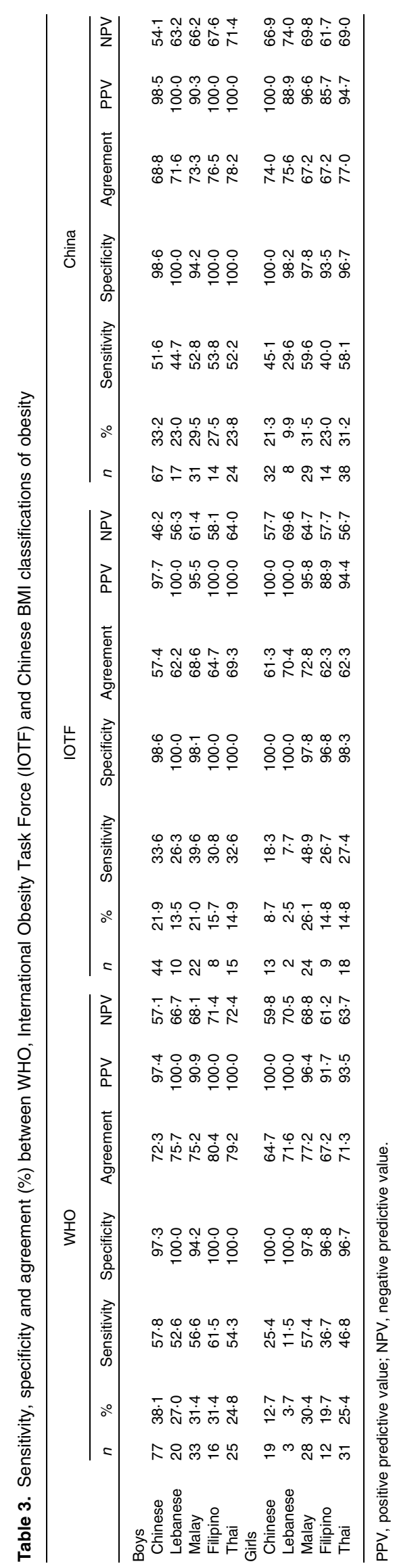


Table 4. Comparison of BMI cut-off points for obesity proposed by the WHO using Caucasian data with calculated BMI equivalents for Chinese, Lebanese, Malay, Filipino and Thai boys and girls derived from regression equations for predicting percentage body fat (\%BF) from $\mathrm{BMI}$

\begin{tabular}{|c|c|c|c|c|c|c|c|}
\hline \multirow[b]{2}{*}{ Age (years) } & \multicolumn{2}{|c|}{ Caucasian } & \multicolumn{5}{|c|}{ Predicted BMI equivalent $\left(\mathrm{kg} / \mathrm{m}^{2}\right)$} \\
\hline & BMI $\left(\mathrm{kg} / \mathrm{m}^{2}\right)^{*}$ & \%BFt & Chinese & Lebanese & Malay & Filipino & Thai \\
\hline \multicolumn{8}{|l|}{ Boys } \\
\hline 8 & 19.7 & 21.9 & $16 \cdot 4$ & $16 \cdot 8$ & $15 \cdot 8$ & $16 \cdot 6$ & $15 \cdot 7$ \\
\hline 9 & 20.5 & 22.5 & $16 \cdot 6$ & 17.0 & $16 \cdot 0$ & $16 \cdot 9$ & $16 \cdot 0$ \\
\hline 10 & 21.4 & 23.1 & $16 \cdot 9$ & $17 \cdot 2$ & $16 \cdot 3$ & $17 \cdot 3$ & $16 \cdot 3$ \\
\hline \multicolumn{8}{|l|}{ Girls } \\
\hline 8 & $20 \cdot 6$ & 26.9 & $17 \cdot 2$ & $17 \cdot 0$ & 16.5 & $16 \cdot 4$ & $15 \cdot 8$ \\
\hline 9 & 21.5 & 27.6 & 17.5 & $17 \cdot 3$ & $16 \cdot 8$ & $16 \cdot 8$ & $16 \cdot 1$ \\
\hline 10 & $22 \cdot 6$ & 28.5 & 17.9 & $17 \cdot 7$ & $17 \cdot 3$ & 17.4 & 16.5 \\
\hline
\end{tabular}

${ }^{*}$ BMI cut-offs for obesity proposed by the WHO for school-aged children and adolescents ${ }^{(16)}$

† Corresponding value of \% $\mathrm{BF}$ predicted from the Caucasian equation from $\mathrm{BMI}^{(24)}$

we hypothesised that the body composition of children in this cohort would be similar to the European population with a lower \% BF than the Asian population at a given BMI. However, no significant difference in BMI-\%BF relationship was found among Chinese, Lebanese and Malay children.

As indicated in the present results, the ethnic difference in the BMI-\%BF relationship among the five Asian countries studied varied by BMI. Some studies conducted among white, Hispanic and Asian populations have also reported that the relationship between $\mathrm{BMI}$ and \%BF varies by $\mathrm{BMI}$ category $^{(7,28-30)}$. Relatively thin Asian children tend to have a higher $\% \mathrm{BF}$, while overweight Asian children tend to have lower \%BF compared with their white counterparts at a given BMI and age ${ }^{(7)}$. Hispanic youths have less body fat than whites at a BMI $<20 \mathrm{~kg} / \mathrm{m}^{2}$, but more body fat at a BMI $>20 \mathrm{~kg} / \mathrm{m}^{2(29)}$. The interaction between BMI and ethnicity in the estimation of body fatness indicates that it may be difficult to identify equivalent levels of body fatness by simply adjusting BMI for the average difference in body fatness across ethnicity groups ${ }^{(31)}$.

The present results also indicate that Asian children had higher \%BF than Caucasian children at an equivalent level of BMI, age and sex. When a Caucasian prediction formula developed in Dutch children aged $7-15$ years $^{(24)}$ was used to predict the $\% \mathrm{BF}$ from $\mathrm{BMI}$, age and sex, the predicted $\% \mathrm{BF}$ was lower than the measured $\% \mathrm{BF}$, by $6.6 \%$ for Chinese, $6.0 \%$ for Lebanese, $6.9 \%$ for Malays, $5.9 \%$ for Filipinos and $7.9 \%$ for Thais. Caucasian equations generally show a remarkable underestimation when used in Asian populations. For example, Gurrici et al. ${ }^{(27)}$ indicated that the prediction formula developed in the Dutch population underestimated \%BF by $5 \cdot 8$ (SD 4.8) and $7 \cdot 7$ (SD 3.8) \% in male and female Malay Indonesians, and by 1.3 (SD 3.0) and 1.7 (SD 3.7) \% in male and female Chinese Indonesians. These results are in agreement with the studies in which the ethnic difference in measured $\% \mathrm{BF}$ and BMI relationship was determined between Caucasians and Asians. Caucasians had a lower \%BF (as determined by dual-energy X-ray absorptiometry, the four-compartment model and ${ }^{2} \mathrm{H}$ dilution technique) than Asians at a given BMI level among children ${ }^{(8-10,25)}$ and adults ${ }^{(2-4,32-34)}$.

Several factors might be responsible for the dependency of the relationship between $\% \mathrm{BF}$ and $\mathrm{BMI}$ on ethnicity, including differences in relative leg length or relative sitting height, frame size and physical activity level. The groups with a higher relative leg length and bigger frame have a lower $\% \mathrm{BF}$ at the same BMI. Caucasians have a higher relative leg length and bigger frame than Asians ${ }^{(27,35,36)}$. Studies on the difference in body build among Asian populations are limited. In a study conducted in Malay and Chinese Indonesians, Malay Indonesians had a higher slenderness index (height/ sum of wrists and knee widths) compared with Chinese Indonesians ${ }^{(27)}$. The groups with a higher activity level might have a higher proportion of muscle mass, meaning less body fat at the same body weight ${ }^{(27,37)}$. However, no physical activity data were collected in the present study. Moreover, those with the same ethnic background living in different places differ in BMI-\%BF relationship, indicating that environmental and socio-economic factors also contribute to the BMI-\%BF relationship. For example, both Chinese Singaporeans and Chinese Americans had a higher \%BF than Chinese living in mainland China at a given $\mathrm{BMI}^{(8,10)}$. African-Americas also showed a higher \%BF than those living in Africa ${ }^{(37)}$.

In the present study, a Caucasian equation was employed to predict the corresponding \%BF from BMI thresholds for obesity proposed by the $\mathrm{WHO}$, and then the equivalent BMI values were recalculated for our participants using the ethnic-specific equation. The present results suggest that the BMI thresholds proposed by the WHO need to be lowered by 3-6 units for Asian children. Previous studies also employed Caucasian equations to derive the corresponding BMI for obesity among children and adults in other ethnic groups ${ }^{(26,30,33,38)}$. Similar to the present study, BMI cut-offs for obesity for Taiwanese, Indians, Malays and Chinese adults should be lowered compared with those for Caucasians.

In the present study, measuring obesity by BMI using WHO and IOTF criteria had low sensitivity in identifying obesity measured by \%BF. One of the main reasons for the low sensitivity might be the population used for developing BMI cutoffs. The WHO proposed BMI cut-off points ranging from 18.3 to $29 \cdot 7 \mathrm{~kg} / \mathrm{m}^{2}$ for children and adolescents aged 5-19 years in 2007 , which correspond to the adult obesity threshold of $30 \mathrm{~kg} / \mathrm{m}^{2}$. These cut-offs were developed from data from the US population. The IOTF has also developed international BMI cut-off points for obesity by sex for children 
and adolescents aged 2-18 years, defined to pass through the BMI of $30 \mathrm{~kg} / \mathrm{m}^{2}$ at the age of 18 years. Although the IOTF BMI classification was derived using data from Brazil, Great Britain, Hong Kong, The Netherlands, Singapore and the USA, the sensitivity is even lower than the WHO classification. Among the countries involved in the present study, only China has its own age- and sex-specific BMI classification. The Chinese BMI cut-off values are slightly higher than the WHO cut-offs in boys while lower than the WHO cut-offs in girls. These lower BMI cut-offs increase the sensitivity by $19 \cdot 7,18 \cdot 1,2 \cdot 2$, 3.3 and $11.3 \%$ for Chinese, Lebanese, Malay, Filipino and Thai girls, respectively. It can be suggested from the present results that, as lower BMI cut-offs were proposed for Asian adults, BMI cut-offs for Asian children should be lowered when the BMI is used as a screening tool for overweight and obesity in this population.

There are some limitations in the present study. First, despite the large sample ( $n$ 1039), it was not randomly selected and may not be representative of the general population. However, we gained a better understanding of the BMI-\%BF relationship because participants were representative of a wide BMI range. Second, despite the validity of the ${ }^{2} \mathrm{H}$ dilution technique for the assessment of TBW and subsequent prediction of $\% \mathrm{BF}$ using the two-compartment model, a bias may have occurred due to violation of the assumptions of the technique. The primary assumption is FFM has a constant hydration fraction; however, this may differ among ethnic groups. However, to date, there is no published information on the ethnic-specific hydration of the FFM. Moreover, the ${ }^{2} \mathrm{H}$ dilution technique is the only option for the remote measurement of body composition with high precision. In addition, we know very little about the ethnic variation in health risk across $\% \mathrm{BF}$ ranges and there is no widely accepted classification of excess body fat among children. It is clear that there is an urgent need to describe the dose-response relationship between $\% \mathrm{BF}$ and health risk in children and adolescents in different ethnic groups. However, the delayed onset of numerous health conditions related to obesity during childhood and adolescence makes this work very difficult.

In conclusion, the present study demonstrated that the relationship between $\mathrm{BMI}$ and $\% \mathrm{BF}$ differs by ethnicity among Asian children. This suggests that the application of a single BMI cut-off point may not be appropriate to screen for health risks in all Asian children. Nonetheless, Asian children had a greater \%BF than Caucasian children at any given BMI, suggesting that the former may be at higher risk of developing obesity-related health conditions at lower BMI values. These ethnic differences in the BMI-\%BF relationship should be considered when BMI is used as a screening tool for obesity in epidemiologic studies and in clinical settings.

\section{Acknowledgements}

The present study was supported by the International Atomic Energy Agency (no. RAS/6/050). The authors would like to acknowledge Ms Connie Wishart for her work in the analysis of urine samples.
A. L. contributed to data collection in China, data analysis and drafted the manuscript. A. P. H. contributed to the design, interpretation of data and revising the manuscript. N. M. B. contributed to the design, interpretation of data and revising the manuscript. M. K. contributed to the analysis of samples and revising the manuscript. G. M., M. N. I., K. K., L. N. and T. P. T. were the principal investigators in their respective countries and contributed to data collection and interpretation and revising the manuscript. B. K. P. contributed to data collection and interpretation in Malaysia and revising the manuscript.

All authors claimed no conflicts of interest.

\section{References}

1. World Health Organization (2004) Appropriate body-mass index for Asian populations and its implications for policy and intervention strategies. Lancet 363, 157-163.

2. Deurenberg P, Yap M \& van Staveren WA (1998) Body mass index and percent body fat: a meta analysis among different ethnic groups. Int J Obes 22, 1164-1171.

3. Gurrici S, Hartriyanti Y, Hautvast J, et al. (1998) Relationship between body fat and body mass index: differences between Indonesians and Dutch Caucasians. Eur J Clin Nutr 52, 779-783.

4. Wang J, Thornton JC, Russell M, et al. (1994) Asians have lower-body mass index (BMI) but higher percent body-fat than do whites - comparisons of anthropometric measurements. Am J Clin Nutr 60, 23-28.

5. Daniels SR, Khoury PR \& Morrison JA (1997) The utility of body mass index as a measure of body fatness in children and adolescents: differences by race and gender. Pediatrics 99, 804-807.

6. Going S, Nichols J, Loftin M, et al. (2006) Validation of bioelectrical impedance analysis (BIA) for estimation of body composition in black, white and Hispanic adolescent girls. Int J Body Compos Res 4, 161-167.

7. Freedman D, Wang J, Thornton J, et al. (2008) Racial/ethnic differences in body fatness among children and adolescents. Obesity (Silver Spring) 16, 1105-1111.

8. Deurenberg P, Deurenberg-Yap M, Foo LF, et al. (2003) Differences in body composition between Singapore Chinese, Beijing Chinese and Dutch children. Eur J Clin Nutr 57, 405-409.

9. Mehta S, Mahajan D, Steinbeck KS, et al. (2002) Relationship between measures of fatness, lipids and ethnicity in a cohort of adolescent boys. Ann Nutr Metab 46, 192-199.

10. Navder KP, He Q, Zhang X, et al. (2009) Relationship between body mass index and adiposity in prepubertal children: ethnic and geographic comparisons between New York City and Jinan City (China). J Appl Physiol 107, 488-493.

11. Rush EC, Scraqq R, Schaaf D, et al. (2009) Indices of fatness and relationships with age, ethnicity and lipids in New Zealand European, Māori and Pacific children. Eur J Clin Nutr 63, 627-633.

12. He Q, Horlick M, Thornton J, et al. (2004) Sex-specific fat distribution is not linear across pubertal groups in a multiethnic study. Obes Res 12, 725-733.

13. Guo S, Chumlea W, Roche A, et al. (1997) Age- and maturityrelated changes in body composition during adolescence into adulthood: The Fels Longitudinal Study. Int J Obes 21, $1167-1175$. 
14. Deurenberg-Yap M, Schmidt G, van Staveren WA, et al. (2000) The paradox of low body mass index and high body fat percentage among Chinese, Malays and Indians in Singapore. Int Obes Relat Metab Disord 24, 1011-1017.

15. Cole T, Bellizzi M, Flegal K, et al. (2000) Establishing a standard definition for child overweight and obesity worldwide: international survey. BMJ (Clin Res Ed) 320, 1-6.

16. de Onis M, Onyango AW, Borghi E, et al. (2007) Development of a WHO growth reference for school-aged children and adolescents. Bull World Health Organ 85, 660-667.

17. Group of China Obesity Task Force (2004) Body mass index reference norm for screening overweight and obesity in Chinese children and adolescents. Chin J Epidemiol 25, 97-102.

18. Tanner J \& Whitehouse R (1976) Clinical longitudinal standards for height, weight, height velocity, weight velocity, and stages of puberty. Arch Dis Child 51, 170-179.

19. Lohman TG (1986) Applicability of body composition techniques and constants for children and youths. Exerc Sport Sci Rev 14, 325-357.

20. Tabachnick BG \& Fidell LS (2007) Using Multivariate Statistics, 5th ed. Boston: Pearson/Allyn \& Bacon.

21. Garrow JS \& Webster JD (1985) Quetelets's index $\left(\mathrm{W} / \mathrm{H}^{2}\right)$ as a measure of fatness. Int J Obes 9, 147-153.

22. Kagawa M, Kerr D, Uchida H, et al. (2006) Differences in the relationship between BMI and percentage body fat between Japanese and Australian-Caucasian young men. Br J Nutr 95, $1002-1007$.

23. Williams DP, Going SB, Lohman TG, et al. (1992) Body fatness and risk for elevated blood pressure, total cholesterol, and serum lipoprotein ratios in children and adolescents. Am J Public Health 82, 358-363.

24. Deurenberg P, Weststrate J \& Seidell J (1991) Body mass index as a measure of body fatness: age- and sex-specific prediction formulas. Br J Nutr 65, 105-114.

25. Duncan JS, Duncan EK \& Schofield G (2009) Accuracy of body mass index (BMI) thresholds for predicting excess body fat in girls from five ethnicities. Asia Pacific J Clin Nutr 18, 404-411.

26. Deurenberg-Yap M, Schmidt G, van Staveren WA, et al. (2000) The paradox of low body mass index and high body fat percentage among Chinese, Malays and Indians in Singapore. Int J Obes Relat Metab Disord 24, 1011-1017.
27. Gurrici S, Hartriyanti Y, Hautvast J, et al. (1999) Differences in the relationship between body fat and body mass index between two different Indonesian ethnic groups: the effect of body build. Eur J Clin Nutr 53, 468-472.

28. Fernández JR, Heo MS, Heymsfield SB, et al. (2003) Is percentage body fat differentially related to body mass index in Hispanic Americans, African Americans, and European Americans? Am J Clin Nutr 77, 71-75.

29. Wang WC \& Bachrach LK (1996) Validity of the body mass index as an indicator of adiposity in an ethnically diverse population of youths. Am J Hum Biol 8, 641-651.

30. Swinburn BA, Ley SJ, Carmichael HE, et al. (1999) Body size and composition in Polynesians. Int J Obes Relat Metab Disord 23, 1178-1183.

31. Freedman DS \& Sherry B (2009) The validity of BMI as an indicator of body fatness and risk among children. Pediatrics 124, S23-S34.

32. Deurenberg P, Deurenberg-Yap M \& Guricci S (2002) Asians are different from Caucasans and from each other in their body mass index/body fat per cent relationship. Obes Res 3, 141-146.

33. Chang CJ, Wu CH, Chang CS, et al. (2003) Low body mass index but high percent body fat in Taiwanese subjects: implications of obesity cutoffs. Int J Obes 27, 253-259.

34. Chung SC, Song MY, Shin HD, et al. (2005) Korean and Caucasian overweight premenopausal women have different relationship of body mass index to percent body fat with age. J Appl Physiol 99, 103-107.

35. Deurenberg P, Yap MD, Wang J, et al. (1999) The impact of body build on the relationship between body mass index and percent body fat. Int J Obes 23, 537-542.

36. Norgan NG (1994) Interpretation of low body mass indices: Australian Aborigines. Am J Phys Anthropol 94 $229-237$

37. Luke A, DurazoArvizu R, Rotimi C, et al. (1997) Relation between body mass index and body fat in black population samples from Nigeria, Jamaica, and the United States. $A m J$ Epidemiol 145, 620-628.

38. Rush EC, Puniani K, Valencia ME, et al. (2003) Estimation of body fatness from body mass index and bioelectrical impedance: comparison of New Zealand European, Maori and Pacific Island children. Eur J Clin Nutr 57, 1394-1401. 